\title{
Outcomes of the 10th EGU Plinius Conference on Mediterranean Storms (2008)
}

\author{
S. C. Michaelides, K. Savvidou, A. Orphanou, K. Nicolaides, and F. Tymvios \\ Meteorological Service, Nicosia, Cyprus
}

\begin{abstract}
This paper comprises a comprehensive account on the outcomes of the 10th Plinius Conference on Mediterranean Storms that was held in Cyprus from 22 to 24 September 2008. Selected papers presented during the Conference were published in two peer reviewed journals that were devoted to this event and are summarized in this concise report.
\end{abstract}

\section{Introduction}

The Plinius Conference on Mediterranean Storms is thematic scientific forum supported by the European Geosciences Union (EGU). This series of Conferences was initiated in 1999 as an effort by mostly Italian scientists; since 2002, the Plinius series of Conferences are under the auspices of the Natural Hazards Division of EGU.

The Plinius Conferences are organized as a series of successful scientific events which were originally planned and designed to serve as specialized international fora for "in-depth, multi-disciplinary discussions concerning the scientific aspects of natural hazards associated with severe storms in the Mediterranean basin". However, through the years, the Plinius Conference has evolved into a broader forum for scientific discussions and debates, attracting scientists, not only from the Mediterranean region but also from many parts of the World; hence, the Plinius Conference is now an established, reputable and international scientific forum for presenting scientific findings on hazardous weather and weather related natural hazards, focusing on the Mediterranean region.

The 10th Plinius Conference (see http://meetings. copernicus.org/plinius10/) was held from 22 to 24 September 2008 at the University of Cyprus in Nicosia, the capital of Cyprus, a country with more than ten thousand years of

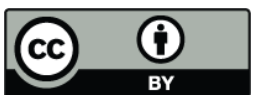

Correspondence to: S. C. Michaelides (silas@ucy.ac.cy)
Mediterranean history. The decision to host the 10th Plinius Conference in Cyprus was taken by the Steering Committee in 2006, during the 8th Plinius Conference.

Over the years, the various editions of the Plinius Conference on Mediterranean Storms have provided a crucial contribution in improving our understanding of storms over the Mediterranean area and of their ground effects. The objective of the 2008 Conference (the 10th of the series) was to provide an interdisciplinary forum for discussion of the present state of knowledge, as well as of the advances in research and application disciplines related to Mediterranean storms, such as: nature and physical processes of these extreme events; expected changes in relationship to predicted climate changes; advanced techniques to observe, monitor and forecast these storms; their relationships to coupled surface processes and effects, with particular emphasis on damaging floods and landslides; and, finally, the socioeconomical implications.

In order to appreciate the multi-disciplinary approach adopted by the recent Plinius Conferences in the study of the above phenomena, the twelve topics of the 2008 Conference were decided as follows: Climate Change and Extreme Events, Storm Processes, Mesoscale Modeling, Remote Sensing, Nowcasting, Operational Meteorological Forecasting, Rainfall Downscaling, Soil-Vegetation-Atmosphere Interactions, Hydrological Processes, Operational Hydrological Forecasting, Prediction and Effects of Rainfall-Induced Landslides and Societal Impacts and Responses.

The local organization of the 10th Plinius Conference was undertaken by a group of twelve competent colleagues and associates from the Meteorological Service of Cyprus, the Cyprus Meteorological Association, the University of Cyprus and CNR, ISAC, (National Research Council, Institute of Atmospheric Sciences and Climate), Rome, Italy. A panel of twenty-four experts of International reputation who, as members of the Scientific Committee, reviewed the submitted abstracts, helped in the scientific programme organization and convened the various sessions managed the scientific aspects of the Conference.

Published by Copernicus Publications on behalf of the European Geosciences Union. 
The Conference was successful. More than 150 participants from 15 countries attended the meeting. A total of 126 papers were accepted for presentation during this Conference, 84 of which were presented orally and the remaining 42 in the poster sessions. In line with the objectives of the Plinius Conference and following the recommendations of the Scientific Committee, seven invited experts of international reputation were asked and delivered keynote presentations on their respective fields of expertise. All of the papers presented were published in an Abstracts Volume that was made available to participants both in printed and electronic forms.

Selected papers from those presented at the Conference have been published in two special issues of peerreviewed journals: twenty-four papers comprise a Special Issue of Natural Hazards and Earth System Sciences (papers were published in Volumes 9 and 10), entitled "Advances in Mediterranean Meteorology" (http://www. nat-hazards-earth-syst-sci.net/special_issue89.html) and sixteen papers comprise Volume 23 of Advances in Geosciences, entitled "10th EGU Plinius Conference on Mediterranean Storms (2008)" (http://www.adv-geosci.net/ 23/index.html).

In the following, the content and the main results of the papers published in the Natural Hazards and Earth System Sciences and Advances in Geosciences special issues are summarized. The authors of the present paper acted as Guest Editors of these two publications.

For a comprehensive outline of all the papers that were published in these two volumes, a grouping was made of the studies reported: (a) Diagnostic studies, (b) Modeling studies, (c) Remote sensing studies, and (d) Statistical studies.

\section{Diagnostic studies}

A large share of studies in this group was devoted to the study of heavy precipitation, the underlying processes and the effects at ground level. Kaspar and Müller (2009) examined the relationship of the synoptically driven heavy rain in the Mediterranean region with the occurrence of synopticdynamic anomalies. The periods of heavy rains in both the Mediterranean region and Central Europe were characterized by the occurrence of anomalies that created synoptic-scale conditions favorable for triggering and sustaining heavy rain. Ramis et al. (2009) analyzed the observational information for the extreme event of 4 October 2007 in Mallorca, Spain, which resulted in extensive damage and loss of one life. Results show that most observations suggest the presence of highly amplified gravity waves that could have initiated convection. The amplitude of the gravity waves may have produced enough ascent for convectively unstable layers to release convection. Cattani et al. (2009) studied the relationship between cloud optical and microphysical characteristics and rainfall intensity for convective storms over the Mediterranean. They produced, on the one hand, a cloud optical thickness threshold value beyond which precipitation initiates and, on the other hand, an effective radius range for the identification of the precipitating cloud. Zangvil et al. (2010) considered water vapor budget analysis as a powerful tool for studying and understanding processes leading to precipitation. In their study, a comparison was made between water vapor budget over United States Midwest and Southern Great Plains, on the one hand, and over the eastern Mediterranean Sea, on the other hand, during their seasons of maximum precipitation. Despite the inter-regional differences in time of year, size of region, and surface characteristics, the water vapor budget over these areas was found to have common features. Bodini and Cossu (2010) studied the heavy rainfall events that caused flash flooding and landslides over CentralEast Sardinia in order to support the land use planning and the application of suitable prevention systems. Results showed significant trends in extreme events at a seasonal scale and the vulnerability of the area based on the timereturn level assessment. Llasat et al. (2010) presented a preliminary analysis of flood risk in Mediterranean countries. Flood events, recorded between 1990 and 2006 in the Mediterranean region, have been included in their study. Records from several international projects and data contained in scientific papers formed the main source for building the respective flood events' database in an attempt to create, for the first time, a verified and complete single database for the entire Mediterranean region. The spatial and temporal distribution of flood events, as well as their social impact, have been analyzed in detail. Nastos et al. (2010) examined the relationship between the recorded precipitation changes and the erosion in Naxos Island, Greece, with the use of precipitation indices, during the period 1955-2007. They showed that the climatic changes in precipitation and the changes in land cover and use are the main drivers for the erosion. Louka et al. (2010) presented their investigation on a case of an intense snowfall in Athens, Greece between 16 and 18 February 2008. The main factor causing the event at its start was the entrainment of arctic air masses from NorthEastern Europe. At a next stage, the effect of Aegean Sea, the existing extremely cold air masses aloft and the enrichment of the air with humidity and heat led to the enhancement of the snowfall in Athens. In the final stage of the event, the local topographical conditions resulted in the occurrence of very intense snowfall.

Four papers focused on the use of lightning data or lightning related indices. Lagouvardos et al. (2009) performed as assessment of the ZEUS lightning detection network (see Kotroni and Lagouvardos, 2008) by comparing it with LINET lightning detection network (see Betz et al., 2009). Their study revealed that ZEUS presents a mean location error of $\sim 6.8 \mathrm{~km}$, detects intra-cloud strokes and under-detects lightning during night; they also concluded 
that the ZEUS data can be used as a good indicator of lightning activity. Katsanos et al. (2009) studied the relationship between lightning and simulated parameters of cloud, using lightning data from the ZEUS lighting detection network (see Kotroni and Lagouvardos, 2008) and the dynamical and microphysical parameters from the non-hydrostatic MM5 (Dudhia, 1993) model outputs. The results showed a poor relationship between lightning and temporal distribution of convective rainfall but a good relationship with the temporal distribution of the simulated concentrations of solid hydrometeors. Michaelides et al. (2010a) explored statistical relationships between the number of lightning recorded by a network of lightning detectors and the amount of rainfall recorded by a network of automatic rain gauges, during rainy events in Cyprus. The study aimed at revealing possible temporal and spatial "relationships" between rainfall and lightning intensities. The search for temporal and spatial relationships between lightning and rainfall was made by considering various timelags between lightning and rainfall, and by varying the area around the rain gauge which the lightning data set refers to. Harats et al. (2010) proposed and evaluated two new indices, aiming at assessing the potential for heavy precipitation and flash-floods. The first is a lightning index and the second is a new rain index expressed as the integrated product of specific humidity and vertical velocity. Three flash flood events, two in Israel and one in Greece, were analyzed, using these indices. Comparison between the observed rain and lightning, on the one hand, and the respective indices, on the other hand, indicated a good agreement with respect to timing and spatial distribution.

A number of authors studied the synoptic scale and thermodynamic processes in the atmosphere and their relation to high-impact weather conditions. Nicolaides et al. (2010a) performed an extensive study of a synoptic case of a baroclinic depression that affected Cyprus between 28 and 29 January 2008, resulting in extreme weather conditions. In particular, they investigated the synoptic, dynamic, energetic and thermodynamic characteristics of this important case. Also, Nicolaides et al. (2010b) investigated the synoptic and dynamic characteristics of the depressions which affected the area of Cyprus during the hydrological year 2007-2008 which is the second drier in Cyprus since records are kept (for more than one hundred years). The authors compared the investigated depressions characteristics with those from previous studies and they concluded that the main reason for the low level of accumulated precipitation over Cyprus was the small number of depressions which affected the area during the study period. Savvidou et al. (2010a) performed an analysis of several instability indices and parameters for thunderstorm events during the period from 1997 to 2001 in Cyprus. By calculating the median, the lower and upper limits, as well as the lower and upper quartiles of the values of these indices, the main characteristics of their distribution were determined. Using thresholds for these indices, thunderstorm events in the above period were characterized as extreme or non-extreme. Orphanou et al. (2010) analyzed the monthly statistical characteristics of jetlet and tropopause in relation to the development of thunderstorms over Cyprus for an 11year period, from 1997 till 2007. Using radiosonde data, the height and the temperature of the tropopause, and the height, wind direction and speed of the jetlet were estimated. The days in the above period with observed thunderstorms were statistically related to the aforementioned characteristics of the jetlet and tropopause. Koletsis et al. (2009) studied the interaction of the northern wind flows with the mountains of Crete Island, Greece. They were able to shown that such an interaction produces an upstream deceleration, a leftward deflection of the air as this approaches the mountains and an intensification of the winds at the southern coasts accompanied with a temperature increase.

\section{Modeling studies}

The large majority of studies in this group dealt with limited area modeling and parametarization. Papadopoulos and Katsafados (2009) reviewed and verified the upgraded Poseidon forecasting system at the Hellenic Centre for Marine Research, using quantitative statistics. The statistics were based on verification against surface observations from the World Meteorological Organization network across the eastern Mediterranean region and showed that the new system demonstrated improvements in weather forecasts. Campo et al. (2009) introduced a coupling framework in which the surface energy budget model, ACHAB (see Caparrini et al., 2004) and the limited area atmospheric model, RAMS (see Tremback, 1990), interact. ACHAB assimilates remotely sensed maps of Land Surface Temperature, in order to retrieve parameters that describe energy balance at the ground surface in the Tuscany region, central Italy, during summer 2005. Results showed improvements in the reconstruction of the surface states by the atmospheric model and considerable influence on the atmospheric dynamics. Davolio et al. (2009) used a number of high resolution, convection resolving models to investigate the flash flood events near Venice. A strong sensitivity to initial and boundary conditions and to model parameterization schemes has been found. Although low predictability was expected due to the convective nature of rainfall, the forecasts made more than $24 \mathrm{~h}$ in advance indicated that the larger scale environment driving the dynamics of this event played an important role in favoring the achievement of a relatively good accuracy in the precipitation forecasts. A verification of the Italian operational limited area model (COSMO17) by Molini et al. (2009) was based on the analysis of the severe weather events over Italy in 2006. This showed that long-lived events are less affected by overall uncertainty than short-lived ones, yet the inner uncertainty 
of the events affects both. Fiori et al. (2009) investigated how the uncertainty in the numerical weather prediction of severe weather events could be affected by increasing the model grid resolution and by choosing a parameterization which is able to represent turbulent processes at such finer scales. Pichelli et al. (2010) investigated the ability of high resolution meso-scale model (MM5, see Tremback, 1990) in reconstructing high resolution water vapor fields over the urban area of Rome, Italy, and its surroundings. Results showed that the high resolution Integrated Water Vapour model maps are in good agreement with the Interferometric Synthetic Aperture Radar ones. Cane and Milelli (2010) used the Multimodel SuperEnsemble technique for quantitative precipitation forecasts in Piemonte region. They involved a new accurate statistical method for bias correction and a wide spectrum of results over Piemonte very dense non-GTS weather station network. Lynn and Yair (2010) modified the Lightning Potential Index (LPI) so as to become gridscale "transparent" between 1- and 4-km grid resolution. The Lightning Potential Index (a measure of the potential for charge generation and separation which leads to lightning flashes in convective thunderstorms) was calculated from the Weather Research and Forecasting model's simulated updraft and microphysical fields. Applied to two case studies and using also lightning measurements, they found that a linear correlation between the lightning density and the time-averaged values of computed LPI could be established. Savvidou et al. (2010b) verified the BOLAM (BOlogna Limited Area Model, see Buzzi et al., 1994; Buzzi and Foschini, 2000) weather prediction model over the area of Cyprus, using data from three automatic weather stations. The parameters verified were temperature, wind speed and precipitation. Also, they performed an analysis of a specific case study that showed the ability of the model to provide accurate forecasts for events producing high-impact weather. In his study, Yano (2010) dealt with the downscale parameterization as a perspective from multi resolution analyses. The article remarks that it is essential to consider the downscaling and parameterization as an "inverse" of each other: downscaling seeks for details in the sub grid-scale processes, while the parameterization seeks for an integrated effect of the former into the resolved scales.

Two papers in this group refer to the use of climatic models. Giannakopoulos et al. (2010) investigated the impact of global climate change on the temperature and precipitation regime over the island of Cyprus. Their analysis was based on daily output from a Regional Climate Model at a high horizontal resolution $(25 \mathrm{~km})$. Two future periods were simulated and an analysis of the changes associated with the temperature regime and the hydrological cycle, such as mean precipitation and drought duration, was presented. Hatzaki et al. (2010) investigated the linkage between largescale upper air circulation over the greater European area and intense precipitation events over Eastern Mediterranean. They estimated the potential changes in atmospheric patterns in the future, under global warming conditions, based on the B2a IPCC emission scenario, by using the regional climate model HadRM3P and the Global Circulation Model HadAM3P.

\section{Remote sensing studies}

Five papers covered the remote sensing area. Rossa et al. (2010) use the radar-derived quantitative precipitation estimates as flash flood guidance in the context of the Italian Civil Protection flood risk management system. Retalis et al. (2010) found that MODIS optical thickness data (see Kaufman et al., 2003) provide relatively accurate information on the aerosol loading over Cyprus. Also, visibility measurements were used as a supplementary source of information for atmospheric loading. Papadavid et al. (2009) examined the integrated use of satellite remote sensing and meteorological data for estimating crop water requirements over agricultural areas of Cyprus. The results showed the minimum and maximum water that crops required; based on these calculations irrigation scheduling can be planned. Hadjimitsis et al. (2010) showed that in order to retrieve accurate vegetation indices and evapotranspiration from satellite remotely sensed data, the impact of the atmosphere should be considered. These corrections could improve the efficiency of water use. Lastly, Hadjimitsis (2010) used remotely sensed imagery, historical hydrological data and meteorological data to examine the linkage between the change in land use and cover, on the one hand, and flood risk, on the other hand, in an urban area in Cyprus, over the past 45 years. Results showed a tremendous urban development in the area under study that had a significant impact on the respective catchment areas.

\section{Statistical studies}

Six studies adopted a statistical approach. Michaelides et al. (2010b) presented a comprehensive application of a methodology developed for the classification of synoptic situations using artificial neural networks. The neural network methodology applied was the SOM architecture (Self Organizing Maps; see Kohonen, 1990) and the dataset used comprises the $500 \mathrm{hPa}$ geopotential height patterns covering a period of 45 years (1957-2002); selected results of the classification were presented. The statistical analysis of the frequency distribution of the classification results for the 36 clusters over the entire 44 -year period revealed significant tendencies in the frequency distribution of certain clusters. Tymvios et al. (2010) investigated the relationship between events of high precipitation in the eastern Mediterranean and the associated geopotential height patterns at $500 \mathrm{hPa}$. Days were classified into clusters of synoptic cases having similar characteristics, by utilizing Kohonen Self Organizing Maps architecture (SOM, see 
Kohonen, 1990). The classification performance was tested by applying the method to extreme rainfall events in the eastern Mediterranean. Stolaki et al. (2009) studied fog event characteristics occurring at the airport of Thessaloniki, using a statistical approach and meteorological data for the period 1971-2005. Fog events were categorized into four types based on physical mechanisms responsible for fog formation. The characteristics of fog were examined in terms of density, duration and their temporal variability. Tzavelas et al. (2010) constructed a threshold model which describes the exceedances over a threshold for the daily precipitation totals over Athens, Greece, using the daily precipitation totals, recorded at the National Observatory of Athens for the period 1891-2005. Also, they used the threshold of $15.8 \mathrm{~mm}$ for the construction of an optimum return level function. Philandras et al. (2010) examined the mean rainfall intensity in Athens and Thessaloniki, Greece, during the period 1930-2007. The trends of the annual and seasonal mean, as well as the maximum rain intensity, were analyzed. Houssos et al. (2009) studied the atmospheric circulation over Europe and the Mediterranean associated with the formation and the dissipation of fog in Greece in the period 1957-2002; 1055 fog events were examined with the application of the S-mode Factor Analysis and k-means Cluster Analysis to the grid point data and as a result, the atmospheric circulations associated with fog events were classified into 10 clusters.

\section{Concluding remarks}

A summary of the outcomes of the 10th Plinius Conference was presented in this paper. Selected papers presented at the Conference were published in two special issues of peer-reviewed journals: a Special Issue of Natural Hazards and Earth System Sciences, entitled "Advances in Mediterranean Meteorology" and Volume 23 of Advances in Geosciences, entitled "10th EGU Plinius Conference on Mediterranean Storms (2008)". We trust that these two volumes will be inspirational to meteorologists and climatologists who are interested in the understanding of the mechanisms underlying extreme weather and will contribute to better knowledge and further research into such natural phenomena.

Acknowledgements. The success of the 10th Plinius Conference was the outcome of valuable contributions from several important factors to whom we wish to express our appreciation and thanks: the members of the Scientific Committee, the session conveners and chairs; the members of the Organizing Committee; the invited speakers for accepting the invitation to present their findings; the sponsors of the Conference and especially the Natural Hazards Division of EGU and its (then) President Bruce Malamud for the generous financial support; the Research Promotion Foundation of Cyprus for its generous grant; the European Meteorological Society for its sponsorship of a travel award; the Meteorological Service for logistic and financial support; the University of Cyprus for offering a state-of-the-art Conference room and its facilities; Copernicus $\mathrm{GmbH}$ for its indispensable interaction and expert assistance in establishing and updating the Web site and the preparation of the Conference Programme, the Abstracts Volume and the special issues of Natural Hazards and Earth System Sciences and Advances in Geosciences. We wish to thank the authors for their contributions and for their active participation in the publication process. We also express our appreciation to the reviewers who have patiently interacted with the Guest Editors. The dedicated scrutiny of all the papers submitted to Natural Hazards and Earth System Sciences by the Supervising Editor Alberto Mugnai is kindly acknowledged. The encouragement of Fausto Guzzetti to write this paper and his valuable comments for improving the draft versions of this paper are greatly appreciated.

\section{References}

Betz, H.-D., Schmidt, K., Laroche, P., Blanchet, P., Oettinger, P., Defer, E., Dziewit, Z., and Konarski, J.: LINET-an international lightning detection network in Europe, Atmos. Res., 91, 564573, 2009.

Bodini, A. and Cossu, Q. A.: Vulnerability assessment of CentralEast Sardinia (Italy) to extreme rainfall events, Nat. Hazards Earth Syst. Sci., 10, 61-72, doi:10.5194/nhess-10-61-2010, 2010.

Buzzi, A. and Foschini, L.: Mesoscale meteorological features associated with heavy precipitation in the southern Alpine region, Meteorol. Atmos. Phys., 72, 131-146, 2000.

Buzzi, A., Fantini, M., Malguzzi, P., and Nerozzi, F.: Validation of a limited area model in cases of Mediterranean cyclogenesis: surface fields and precipitation scores, Meteorol. Atmos. Phys., 53, 137-153, 1994.

Campo, L., Castelli, F., Entekhabi, D., and Caparrini, F.: Landatmosphere interactions in an high resolution atmospheric simulation coupled with a surface data assimilation scheme, Nat. Hazards Earth Syst. Sci., 9, 1613-1624, doi:10.5194/nhess-91613-2009, 2009.

Cane, D. and Milelli, M.: Multimodel SuperEnsemble technique for quantitative precipitation forecasts in Piemonte region, Nat. Hazards Earth Syst. Sci., 10, 265-273, doi:10.5194/nhess-10265-2010, 2010.

Caparrini, F., Castelli, F., and Entekhabi, D.: Variational estimation of soil and vegetation turbulent transfer and heat flux parameters from sequences of multisensor imagery, Water Resour. Res., 40, W12515, doi:10.1029/2004WR003358, 2004.

Cattani, E., Torricella, F., Laviola, S., and Levizzani, V.: On the statistical relationship between cloud optical and microphysical characteristics and rainfall intensity for convective storms over the Mediterranean, Nat. Hazards Earth Syst. Sci., 9, 2135-2142, doi:10.5194/nhess-9-2135-2009, 2009.

Davolio, S., Mastrangelo, D., Miglietta, M. M., Drofa, O., Buzzi, A., and Malguzzi, P.: High resolution simulations of a flash flood near Venice, Nat. Hazards Earth Syst. Sci., 9, 1671-1678, doi:10.5194/nhess-9-1671-2009, 2009. 
Dudhia, J.: A non-hydrostatic version of the Penn State/NCAR mesoscale model: validation tests and simulation of an Atlantic cyclone and cold front, Mon. Weather Rev., 121, 1493-1513, 1993.

Fiori, E., Parodi, A., and Siccardi, F.: Dealing with uncertainty: turbulent parameterizations and grid-spacing effects in numerical modelling of deep moist convective processes, Nat. Hazards Earth Syst. Sci., 9, 1871-1880, doi:10.5194/nhess-9-1871-2009, 2009.

Giannakopoulos, C., Hadjinicolaou, P., Kostopoulou, E., Varotsos, K. V., and Zerefos, C.: Precipitation and temperature regime over Cyprus as a result of global climate change, Adv. Geosci., 23, 17-24, doi:10.5194/adgeo-23-17-2010, 2010.

Hadjimitsis, D. G.: Brief communication "Determination of urban growth in catchment areas in Cyprus using multi-temporal remotely sensed data: risk assessment study", Nat. Hazards Earth Syst. Sci., 10, 2235-2240, doi:10.5194/nhess-10-22352010, 2010.

Hadjimitsis, D. G., Papadavid, G., Agapiou, A., Themistocleous, K., Hadjimitsis, M. G., Retalis, A., Michaelides, S., Chrysoulakis, N., Toulios, L., and Clayton, C. R. I.: Atmospheric correction for satellite remotely sensed data intended for agricultural applications: impact on vegetation indices, Nat. Hazards Earth Syst. Sci., 10, 89-95, doi:10.5194/nhess-10-892010, 2010.

Harats, N., Ziv, B., Yair, Y., Kotroni, V., and Dayan, U.: Lightning and rain dynamic indices as predictors for flash floods events in the Mediterranean, Adv. Geosci., 23, 57-64, doi:10.5194/adgeo23-57-2010, 2010.

Hatzaki, M., Flocas, H. A., Oikonomou, C., and Giannakopoulos, C.: Future changes in the relationship of precipitation intensity in Eastern Mediterranean with large scale circulation, Adv. Geosci., 23, 31-36, doi:10.5194/adgeo-23-31-2010, 2010.

Houssos, E. E., Lolis, C. J., and Bartzokas, A.: The main characteristics of atmospheric circulation associated with fog in Greece, Nat. Hazards Earth Syst. Sci., 9, 1857-1869, doi:10.5194/nhess-9-1857-2009, 2009.

Kaspar, M. and Müller, M.: Cyclogenesis in the Mediterranean basin: a diagnosis using synoptic-dynamic anomalies, Nat. Hazards Earth Syst. Sci., 9, 957-965, doi:10.5194/nhess-9-9572009, 2009.

Katsanos, D. K., Lagouvardos, K., and Kotroni, V.: Relationship between lightning and model simulated microphysical parameters over the central and eastern Mediterranean, Nat. Hazards Earth Syst. Sci., 9, 1719-1726, doi:10.5194/nhess-9-1719-2009, 2009.

Kaufman, Y. J., Ichoku, C., Giglio, L., Korontzi, S., Chu, D. A., Hao, W. M., Li, R.-R., and Justice, C. O.: Fire and smoke observed from the Earth Observing System MODIS instrumentproducts, validation, and operational use, Int. J. Remote Sens., 24, 1765-1781, 2003.

Kohonen, T.: The Self-Organizing Map, Proceedings of IEEE, 78(9), 1464-1480, 1990.

Koletsis, I., Lagouvardos, K., Kotroni, V., and Bartzokas, A.: The interaction of northern wind flow with the complex topography of Crete Island - Part 1: Observational study, Nat. Hazards Earth Syst. Sci., 9, 1845-1855, doi:10.5194/nhess-9-1845-2009, 2009.

Kotroni, V. and Lagouvardos, K.: Lightning occurrence in relation with elevation, terrain slope and vegetation cover in the Mediterranean, J. Geophys. Res., 113, D21118,
doi:10.1029/2008JD010605, 2008.

Lagouvardos, K., Kotroni, V., Betz, H.-D., and Schmidt, K.: A comparison of lightning data provided by ZEUS and LINET networks over Western Europe, Nat. Hazards Earth Syst. Sci., 9, 1713-1717, doi:10.5194/nhess-9-1713-2009, 2009.

Llasat, M. C., Llasat-Botija, M., Prat, M. A., Porcú, F., Price, C., Mugnai, A., Lagouvardos, K., Kotroni, V., Katsanos, D., Michaelides, S., Yair, Y., Savvidou, K., and Nicolaides, K.: High-impact floods and flash floods in Mediterranean countries: the FLASH preliminary database, Adv. Geosci., 23, 47-55, doi:10.5194/adgeo-23-47-2010, 2010.

Louka, P., Boucouvala, D., Gofa, F., Balami, M., and Ziakopoulos, D.: Operational forecasting of a snowfall event over the Greater Athens Area, Adv. Geosci., 23, 25-30, doi:10.5194/adgeo-2325-2010, 2010.

Lynn, B. and Yair, Y.: Prediction of lightning flash density with the WRF model, Adv. Geosci., 23, 11-16, doi:10.5194/adgeo23-11-2010, 2010.

Michaelides, S., Savvidou, K., and Nicolaides, K.: Relationships between lightning and rainfall intensities during rainy events in Cyprus, Adv. Geosci., 23, 87-92, doi:10.5194/adgeo-23-872010, 2010a.

Michaelides, S., Tymvios, F., and Charalambous, D.: Investigation of trends in synoptic patterns over Europe with artificial neural networks, Adv. Geosci., 23, 107-112, doi:10.5194/adgeo-23107-2010, 2010b.

Molini, L., Parodi, A., and Siccardi, F.: Dealing with uncertainty: an analysis of the severe weather events over Italy in 2006, Nat. Hazards Earth Syst. Sci., 9, 1775-1786, doi:10.5194/nhess-91775-2009, 2009.

Nastos, P. T., Evelpidou, N., and Vassilopoulos, A.: Brief communication "Does climatic change in precipitation drive erosion in Naxos Island, Greece?", Nat. Hazards Earth Syst. Sci., 10, 379-382, doi:10.5194/nhess-10-379-2010, 2010.

Nicolaides, K., Orphanou, A., Savvidou, K., Michaelides, S., and Tsitouri, M.: The cold frontal depression that affected the area of Cyprus between 28 and 29 January 2008, Nat. Hazards Earth Syst. Sci., 10, 1913-1925, doi:10.5194/nhess-10-19132010, 2010a.

Nicolaides, K., Savvidou, K., Michaelides, S., and Tsitouri, M.: Synoptic and dynamic characteristics of the depressions that affected the area of Cyprus during the winter of 2007-2008, Adv. Geosci., 23, 101-106, doi:10.5194/adgeo-23-101-2010, 2010b.

Orphanou, A., Nicolaides, K., Charalambous, D., Lingis, P., and Michaelides, S. C.: Tropopause and jetlet characteristics in relation to thunderstorm development over Cyprus, Adv. Geosci., 23, 113-117, doi:10.5194/adgeo-23-113-2010, 2010.

Papadavid, G. C., Agapiou, A., Michaelides, S., and Hadjimitsis, D. G.: Brief communication "The integration of remote sensing and meteorological data for monitoring irrigation demand in Cyprus", Nat. Hazards Earth Syst. Sci., 9, 2009-2014, doi:10.5194/nhess-9-2009-2009, 2009.

Papadopoulos, A. and Katsafados, P.: Verification of operational weather forecasts from the POSEIDON system across the Eastern Mediterranean, Nat. Hazards Earth Syst. Sci., 9, 1299_ 1306, doi:10.5194/nhess-9-1299-2009, 2009.

Philandras, C. M., Nastos, P. T., Paliatsos, A. G., and Repapis, C. C.: Study of the rain intensity in Athens and Thessaloniki, Greece, Adv. Geosci., 23, 37-45, doi:10.5194/adgeo-23-37-2010, 2010. 
Pichelli, E., Ferretti, R., Cimini, D., Perissin, D., Montopoli, M., Marzano, F. S., and Pierdicca, N.: Water vapour distribution at urban scale using high-resolution numerical weather model and spaceborne SAR interferometric data, Nat. Hazards Earth Syst. Sci., 10, 121-132, doi:10.5194/nhess-10-121-2010, 2010.

Ramis, C., Romero, R., and Homar, V.: The severe thunderstorm of 4 October 2007 in Mallorca: an observational study, Nat. Hazards Earth Syst. Sci., 9, 1237-1245, doi:10.5194/nhess-91237-2009, 2009.

Retalis, A., Hadjimitsis, D. G., Michaelides, S., Tymvios, F., Chrysoulakis, N., Clayton, C. R. I., and Themistocleous, K.: Comparison of aerosol optical thickness with in situ visibility data over Cyprus, Nat. Hazards Earth Syst. Sci., 10, 421-428, doi:10.5194/nhess-10-421-2010, 2010.

Rossa, A. M., Cenzon, G., and Monai, M.: Quantitative comparison of radar QPE to rain gauges for the 26 September 2007 Venice Mestre flood, Nat. Hazards Earth Syst. Sci., 10, 371-377, doi:10.5194/nhess-10-371-2010, 2010.

Savvidou, K., Orphanou, A., Charalambous, D., Lingis, P., and Michaelides, S.: A statistical analysis of sounding derived indices and parameters for extreme and non-extreme thunderstorm events over Cyprus, Adv. Geosci., 23, 79-85, doi:10.5194/adgeo-23-79-2010, 2010a.

Savvidou, K., Lagouvardos, K., Michaelides, S., Kotroni, V., and Constantinides, P.: Verification of the BOLAM weather prediction model over the area of Cyprus, Adv. Geosci., 23, 93100, doi:10.5194/adgeo-23-93-2010, 2010b.
Stolaki, S. N., Kazadzis, S. A., Foris, D. V., and Karacostas, Th. S.: Fog characteristics at the airport of Thessaloniki, Greece, Nat. Hazards Earth Syst. Sci., 9, 1541-1549, doi:10.5194/nhess9-1541-2009, 2009.

Tremback, C. J.: Numerical simulation of a mesoscale convective complex, model development and numerical results, Ph.D. thesis, Colorado State University Dept. of Atmospheric Science, Fort Collins, CO 80523, Atmos. Sci. Paper No. 465, 1990.

Tymvios, F., Savvidou, K., and Michaelides, S. C.: Association of geopotential height patterns with heavy rainfall events in Cyprus, Adv. Geosci., 23, 73-78, doi:10.5194/adgeo-23-73-2010, 2010

Tzavelas, G., Paliatsos, A. G., and Nastos, P. T.: Brief communication "Models for the exceedances of high thresholds over the precipitation daily totals in Athens, Greece", Nat. Hazards Earth Syst. Sci., 10, 105-108, doi:10.5194/nhess-10105-2010, 2010.

Yano, J.-I.: Downscaling, parameterization, decomposition, compression: a perspective from the multiresolution analysis, Adv. Geosci., 23, 65-71, doi:10.5194/adgeo-23-65-2010, 2010.

Zangvil, A., Lamb, P. J., Portis, D. H., Jin, F., and Malka, S.: Comparative study of atmospheric water vapor budget associated with precipitation in Central US and eastern Mediterranean, Adv. Geosci., 23, 3-9, doi:10.5194/adgeo-23-3-2010, 2010. 